\title{
ANÁLISE DA PRODUČ̃̃ CIENTÍFICA ACERCA DA FORMAÇÃO CONTINUADA DE DOCENTES DOS INSTITUTOS FEDERAIS
}

\author{
Danise Vivian Goncalves dos Santos, Anne Alilma Silva Souza Ferrete, Luiz Anselmo \\ Menezes Santos \\ *E-mail: nizi_vivian@hotmail.com \\ Instituto Federal de Educação, Ciência e Tecnologia de Sergipe, Brasil \\ DOI: $10.15628 /$ rbept.2020.9097
}

Artigo submetido em out/2019 e aceito em mar/2020

\begin{abstract}
RESUMO
Este trabalho apresenta o estado do conhecimento a respeito da formação docente continuada na educação profissional dos institutos federais, buscando identificar as perspectivas teóricas e características específicas de cada artigo publicado entre 2010 e 2018. A necessidade de investigação surge da problemática apresentada na formação pedagógica dos docentes dos institutos federais, considerando que a maioria, ao ingressar na docência, não possuem formação pedagógica. Os dados levantados foram analisados e interpretados à luz da análise de conteúdo. Os resultados apontam um crescimento nas pesquisas sobre formação docente na educação profissional, após a criação dos institutos federais. Foram identificados poucos relatos de práticas formativas e a necessidade de aprofundamento da teoria acerca da formação docente.
\end{abstract}

Palavras-chave: Educação profissional. Formação continuada. Docência

\section{ANALYSIS PRODUCTION ABOUT THE CONTINUING FORMATION OF TEACHERS OF THE FEDERAL INSTITUTES}

\begin{abstract}
This article presents the state of knowledge regards to continuing teacher education in professional education of the federal institutes (scientific and technological schools in Brazil), to identify the theoretical perspectives in addition to the specified characteristics of each article published between 2010 and 2018. The need for research arises from the problematic presented in the pedagogical training of the professors of the so-called federal institutes, considering that the majority on joining in teaching practice has no pedagogical training. The collected data were analysed and interpretated according to the analysis of content. The results have pointed out arising of the researches on teaching formation in professional education after the implemation of the federal institutes. There were few reports of training practices, but there is need to deepen the theory about teacher education.
\end{abstract}

Keywords: Professional education. Continued training. Teaching 


\section{INTRODUÇÃO}

Realizamos um mapeamento sistemático sobre a formação continuada dos docentes atuantes na educação profissional e tecnológica (EPT), desenvolvida nos institutos federais de educação, ciência e tecnologia. Nessas instituições atuam professores bacharéis, licenciados, tecnólogos, além de técnicos administrativos de diversos níveis e formações.

Tal iniciativa se justifica, por considerarmos o tema relevante e condizente com as especificidades das modalidades da EPT. Tais especialidades compreendem diversos níveis de ensino, inclusive o ensino superior. Acrescente-se também a possibilidade de ampliação da atuação desses profissionais, bem como a necessidade de formação pedagógica para esse atendimento e diversificação da demanda. A partir da reestruturação estabelecida pela lei 11.892/2008, que instituiu a Rede Federal de Educação Profissional, Científica e Tecnológica e criou os institutos federais de educação, a EPT apresenta como finalidade a formação de "[...] cidadãos com vistas na atuação profissional [...] com ênfase no desenvolvimento socioeconômico local, regional e nacional." (BRASIL, 2008). Nesse aspecto, os institutos federais de educação passam a considerar como concepção de educação profissional a integração entre ciência, tecnologia e cultura atrelando-a às dimensões indissociáveis da vida humana. Instiga-se também nesse bojo a construção da autonomia intelectual, do desenvolvimento do caráter cientifico na formação para o mundo do trabalho, com uma intencionalidade formativa, diferentemente do pensamento tecnicista.

Diante do exposto, fica notório que os institutos federais possuem uma organização diferenciada em relação à de outras escolas comuns de currículo generalista. O público destes institutos são adolescentes, jovens e adultos, conforme disposição das diversas modalidades de ensino, de acordo com a já citada lei n. 11.892/2008.

Por sua vez, a lei n. 12.772, de 28 de dezembro de 2012, expõe, dentre outros regimes, o plano de carreira e cargos do magistério dos ensinos básico, técnico e tecnológico (BRASIL, 2012a) e, ao fazê-lo, evidencia as especificidades da atuação de um corpo docente diverso, formado por tecnólogos, licenciados e bacharéis que, muitas vezes, não apresentam uma formação didático-pedagógica consolidada.

Esse quadro remete-nos às pesquisas em torno da formação continuada de professores que têm apresentado diversos objetos de investigação.

No Brasil, na década de 1960, a valorização docente se deu em torno do domínio dos conteúdos. No século XX, na década de 80 , as dimensões sociopolítica e ideológica da prática pedagógica dominaram. Já nos idos dos anos 90, a valorização do professor girou em torno do caráter das práticas de ensino e da didática (SALLES, N.; COSTA; SALLES, F., 2016).

Considerando a recente implantação dos institutos federais revestidos de uma proposta político-pedagógica diferenciada das propostas das antigas 
escolas técnicas (cunho tecnicista), das escolas comuns de currículo generalista e das universidades, os ditos institutos ainda estão em fase de consolidação de identidade institucional. Nesse contexto, o cenário geral de desqualificação da carreira docente tornou-se realidade, por isso o mesmo demanda investigação da prática docente desenvolvida neste espaço da educação profissional.

Nesse sentido, a finalidade deste estudo foi evidenciar as produções sobre a temática da formação continuada de professores na educação profissional dos institutos federais, destacando o fato de que a maioria do corpo docente, neste espaço da educação profissional, possui formação na área técnica.

Os procedimentos metodológicos para a composição do estado do conhecimento aqui detalhado foram realizados a partir de um mapeamento sistemático no portal de periódico da Coordenação de Aperfeiçoamento de Pessoal de Nível Superior (Capes). Critérios de inclusão e exclusão específicos foram adotados e vistos na perspectiva da análise de conteúdo.

Buscou-se, através da pesquisa exploratória e descritiva, efetivar a análise dos trabalhos publicados, identificar que perspectivas teóricas e características de formação continuada estão sendo efetuadas de acordo com publicações do portal de periódicos da Capes referentes aos institutos federais. Para tanto, foram apresentados alguns dos principais pressupostos teóricos a respeito da formação docente em âmbito geral e na educação profissional dos institutos. Na sequência, discutiu-se o desenvolvimento do procedimento metodológico desta revisão sistemática, seguido das discussões acerca do que foi detectado e as considerações finais acerca do problema levantado.

\section{PERSPECTIVAS DA FORMAÇÃO DOCENTE}

A formação docente demanda de investigação e revisão de sua prática. Tal profissão tem sido alvo de desvalorização e desqualificação, bem como banalização da carreira. Alguns autores sistematizaram suas teorias servindo de apoio para fundamentação dos processos de formação de professores. Considerando, pois, os diversos aspectos do estudo sobre a formação e prática docentes, citamos algumas perspectivas teóricas, para embasamento desta pesquisa e análise dos trabalhos selecionados e investigados.

Primeiramente vale ressaltar a epistemologia da prática baseada no processo de "reflexão-na-ação" (SCHON 2000), corroborado pelo pensamento das competências profissionais do professor reflexivo evidenciadas por Perrenoud (2008). Nessa perspectiva teórica, a formação docente baseia-se no conceito de reflexão sobre a prática e é um dos pressupostos utilizados atualmente no campo da formação de professores. Schon (2000) propõe a formação profissional baseada na "epistemologia da prática", em que o profissional é um pesquisador da própria prática, através do processo de "reflexão-na-ação", no qual o profissional constitui um 
arcabouço de experiências, onde será possível a resolução de problemas face a esse conjunto de experiências. A "reflexão-na-ação" consiste numa avaliação durante a prática sem interrompê-la, processo este capaz de provocar atitudes de "improvisação" no desenvolvimento da ação profissional.

Para Schon (2000), o desenvolvimento do exercício da profissionalidade docente perpassa pela capacidade de investigar a própria atividade, numa reflexão sobre a prática profissional, para que, a partir dela, constitua-se o saber-fazer, num processo contínuo de construção das identidades docentes.

Outra perspectiva que aparece no cenário das produções acerca da formação docente diz respeito ao pressuposto dos "saberes docentes", evidenciados por Tardif (2014). O autor reúne os conhecimentos docentes numa articulação de saberes que integram a sua prática profissional, segundo se verifica: 1) Saberes da formação profissional - em que se considera os conhecimentos pedagógicos relacionados às técnicas e métodos de ensino (saber-fazer), legitimados cientificamente e igualmente transmitidos aos professores ao longo do seu processo de formação; 2) Saberes disciplinares - conhecimentos específicos do conteúdo, sendo saberes que se integram à prática docente, através da formação dos professores nas diversas disciplinas oferecidas pela universidade; 3) Saberes curriculares - apresentam-se em forma de programas escolares (objetivos, conteúdos, métodos etc.) que os professores devem aprender e aplicar; 4) Saberes experienciais - resultam do próprio exercício da atividade profissional dos professores. Nesse sentido, "[...] incorporam-se à experiência individual e coletiva sob a forma de habilidades, de saber-fazer e de saber ser." (TARDIF, 2014, p. 39).

Diante do exposto, o autor pressupõe que o saber dos professores é plural e temporal, adquirido tanto através de uma história de vida quanto de uma carreira profissional. Destarte, ensinar supõe aprender a ensinar e aprender progressivamente os saberes necessários, articulados à prática docente (TARDIF, 2014).

Indicando a necessidade de repensar a formação de professores, Pimenta (1999) concebe o ensino como prática social, incitando a necessidade da formação para o exercício da atividade docente. Esta prática não está dissociada dos modos de pensar, planejar e agir com o objetivo de concretizar o ensino e a aprendizagem. Nesse sentido as ações pedagógicas, necessitam de uma reflexão por parte dos professores. Tal reflexão só pode acontecer efetivamente se a mesma tiver sido concebida à luz das teorias.

No que diz respeito à formação continuada, Romanowski (2007) também apresenta algumas possibilidades de sistematização. O autor aborda modalidades de formação continuada, diferenciando as categorias em que o professor faz cursos no espaço de trabalho, onde se adota modalidades formais ou aquelas em que o profissional docente reflete as situações vivenciadas chamando-as de informais. Nesse bojo, aponta-se a necessidade de se enxergar a prática dos professores e suas dificuldades como bases e disparadores da formação continuada. Assim, foram investigadas nos trabalhos buscados as modalidades de formação continuada que estão sendo 
efetivadas nas publicações a respeito da formação docente nos institutos federais.

Nesse ínterim, surgiram alguns pontos que merecem reflexão em torno da formação continuada dos professores dos institutos federais: se os professores licenciados, bacharéis ou tecnólogos dos institutos não adquiriram saberes direcionados à ação docente na universidade, que saberes teriam eles construído? Um arcabouço de saberes provenientes dos "experienciais"? Como estes construiriam os saberes da formação profissional, ligados às técnicas de ensino e pedagógicas? São questões para serem pensadas na construção da carreira docente específica desta área da educação profissional.

Assim, a modalidade da educação profissional está contida neste cenário, levando em consideração os pressupostos de base que identificamos na presente pesquisa. Porém, a mesma possui uma trajetória própria de composição, considerando peculiaridades e necessidades formativas didático-pedagógicas aliadas ao contexto da educação profissional. Ressaltamos e evidenciamos as especificidades de cada perspectiva teórica, mas todas estão aqui dispostas ao entendimento e ao estudo do desenvolvimento do campo da formação docente e sua profissionalidade. Por isso, apresentamos brevemente o histórico dessa formação, bem como o que trata a legislação a esse respeito, no intuito de embasar o olhar na composição do estado de conhecimento em questão.

\section{FORMAÇÃO DOCENTE CONTINUADA: O CONTEXTO DOS INSTITUTOS FEDERAIS DE EDUCAÇÃO, CIÊNCIA E TECNOLOGIA}

A construção da trajetória da formação docente na educação profissional carece de uma maior valorização com as especificidades dessa área, considerando as modificações ocorridas diante da lei 11.892, de criação dos institutos federais para esta modalidade de educação. Discussões e debates sobre a formação de professores para a educação básica são também oportunas, sobretudo para a EPT, que de acordo com Meneses Filho e Costa (2017), completam décadas, sem materializar uma política consolidada e específica de formação para área.

Diante da percepção de cursos voltados para trabalhadores - nos quais quem possuía "o conhecimento técnico" eram os que estavam aptos a "ensinar um oficio" -, até os dias atuais que, numa perspectiva diferente da formação de jovens para o mundo do trabalho, com o princípio educativo referente ao incentivo da construção de autonomia intelectual também para a formação técnica, a formação dos professores necessita de um fortalecimento do caráter pedagógico.

Diante disso, para a consolidação da formação dos docentes na EPT, torna-se importante considerar a discussão de Moura (2008). Este autor realiza uma reflexão sobre a formação docente dos profissionais dessa modalidade federal de educação, alertando para a necessidade de uma maior 
articulação entre os sistemas de ensino os quais deveriam visar ao desenvolvimento de uma formação condizente com as verdadeiras necessidades da sociedade brasileira, além do reconhecimento concernente ao panorama do tipo de profissional que se deseja formar e para qual sociedade.

O docente atuante nos institutos federais nas áreas técnicas, até então, é, na maioria das vezes, profissional bacharel ou tecnólogo de áreas específicas que presta o concurso da carreira docente com o fim de atuar na rede federal dessas instituições de ensino. Os docentes das áreas comuns são profissionais licenciados das áreas correspondentes às disciplinas que lecionam.

O princípio da política pedagógica, neste espaço, constitui-se em ofertar cursos que vão desde a educação básica a graduações tecnológicas, licenciaturas e bacharelados, bem como pós-graduações, trazendo a verticalização numa perspectiva de ir além da oferta simultânea de cursos em diferentes níveis, mas com a preocupação de organização curricular de forma dialogada nos itinerários de formação entre os diferentes cursos. Conforme destaca Pacheco (2011, p. 24), "[...] a transversalidade e a verticalização constituem aspectos que contribuem para a singularidade do desenho curricular nas ofertas educativas dessas instituições."

Consequentemente, esta verticalização para os professores ocorre a partir da oportunidade de atuação docente nos diferentes níveis de ensino, respeitando os limites de formação e titularidade da carreira docente. Isso pode instigar uma melhor compreensão da relação entre prática educacional, pesquisa aplicada e extensão tecnológica. Admite-se dessa maneira uma diversidade de olhares através das singularidades que envolvem a educação profissional.

Para compreendermos melhor o que determina a lei a respeito da formação continuada, sentimos a necessidade de trazer alguns artigos da própria legislação em vigor.

O artigo 62 da Lei de Diretrizes e Bases da Educação Nacional (LDB), lei n. 9.394/96 - incluído recentemente pela lei 12.796, de 2013 - traz algumas exigências de formação para se atuar na educação básica. Fica explícito no referido artigo que a formação continuada dos profissionais da educação poderá acontecer no local de trabalho, em instituições de educação básica e superior (incluindo cursos de educação profissional); em cursos superiores de graduação plena, tecnológica ou de pós-graduação. O primeiro parágrafo dispõe que "[...] a União, o Distrito Federal, os Estados e os Municípios, em regime de colaboração, deverão promover a formação inicial, a continuada e a capacitação dos profissionais de magistério." (BRASIL, 1996). Não há detalhes a respeito do caráter de como seria a formação continuada na educação básica nem na educação profissional. 
Por sua vez, o decreto n. 8.752, de 2016, que instituiu a "Política nacional de formação dos profissionais da educação básica", define que o atendimento às necessidades de formação continuada deve acontecer através de cursos de formação continuada (art.11, VI), mediante integração ensino-serviço, inclusive por meio de residência pedagógica (art. 8, IV). Mas, não destina os mesmos meios à formação específica na educação profissional da Rede Federal de Educação Ciência e Tecnologia, que não apenas está contida na educação básica, mas também nos níveis técnico e superior (BRASIL, 2016).

A resolução n. 6, de 20 de setembro de 2012, definiu as Diretrizes curriculares nacionais para a educação profissional técnica de nível médio. No seu $2^{\circ}$ parágrafo determina que aos

[...] professores graduados, não licenciados, em efetivo exercício na profissão docente ou aprovados em concurso público, é assegurado o direito de participar ou ter reconhecidos seus saberes profissionais em processos destinados à formação pedagógica ou à certificação da experiência docente, podendo ser considerado equivalente às licenciaturas [...]. (BRASIL, 2012b).

Constata-se que a resolução n. 6 possibilita o reconhecimento do saber docente, aproximando-se dos "saberes docentes" levantados por Tardif (2007), trazendo nos incisos I e III a possibilidade de reconhecimento dos saberes ligados à formação profissional, e no inciso II, aos saberes experienciais.

Nesse ínterim, enquanto a LDB de 1996 reconhece os cursos de licenciatura como formação obrigatória para a atuação na educação básica, a resolução específica para a educação profissional técnica de nível médio, que também faz parte da educação básica, traz o reconhecimento dos saberes profissionais dos professores não-licenciados para o exercício da profissão docente. Todavia, a formação continuada em ambos os casos possui o mesmo direcionamento de reconhecer a responsabilidade dos sistemas e instituições de ensino, entendendo que a formação inicial não esgota as possibilidades de aprimoramento profissional do docente.

Com relação aos objetivos dos institutos federais, de colaborarem também com o processo de formação pedagógica em nível de licenciatura em seus cursos, o art. 7ํㅜ da lei 11.892/2008 explicita a carência de "[...] cursos de licenciatura, bem como programas especiais de formação pedagógica, com vistas na formação de professores para a educação básica, sobretudo nas áreas de ciências e matemática, e para a educação profissional." (BRASIL, 2008).

Enfatizamos a necessidade de fortalecimento e aprimoramento das políticas públicas para a formação docente na educação profissional, diante do panorama da formação de professores para a educação profissional desenvolvida nos institutos federais e suas possibilidades de profissionalização baseadas na legislação. Conforme Caldas (2011, p. 36), 
"[...] embora nos últimos anos tenham se ampliado as vozes na defesa da capacitação, não se evidenciaram ainda políticas públicas incisivas e contínuas no sentido de qualificação docente para a EPT." Assim, percebemos um campo que precisa avançar na consolidação das políticas públicas, formação continuada e arcabouço pedagógico dos docentes.

Nesse aspecto questionamos: Como estão atuando as instituições de educação profissional diante dessa demanda? Os institutos federais têm promovido ações de formação continuada para os docentes?

Considerando a problemática apontada, efetivamos uma análise acerca do que dizem as publicações sobre as perspectivas e características dessa formação, buscando colaborar com o entendimento e melhorias desse cenário: formação continuada dos docentes que atuam nos institutos federais.

\section{PROCEDIMENTOS METODOLOGICOS}

Buscando identificar as perspectivas teóricas e características da formação continuada de professores nos trabalhos publicados no portal de periódico da Capes (referentes aos institutos federais), foi levantado o estado do conhecimento sobre a formação continuada dos docentes que atuam na educação profissional, utilizando a base de dados do portal de periódicos em referência. Assegura-se que o

[...] estado de conhecimento é identificação, registro, categorização que levem à reflexão e síntese sobre a produção científica de uma determinada área, em um determinado espaço de tempo, congregando periódicos, teses, dissertações e livros sobre uma temática específica. (MOROSINI, 2015, p. 101).

Para tanto, efetivou-se um mapeamento com os termos "formação continuada" e "instituto federal". De acordo com Koller (2014), as palavraschave necessitam ser precisas o suficiente para se acessar adequadamente o fenômeno.

Para a averiguação e interpretação dos dados, foi utilizada, no primeiro caso, a análise de conteúdo, buscando-se evidenciar as relações existentes dentro do fenômeno estudado. A interpretação, por sua vez, compreendeu abordar um resultado mais amplo, expondo o significado em relação aos objetivos propostos (FRANCO, 2003). Possibilitou-se, dessa maneira, o alcance dos resultados do estudo.

$\mathrm{Na}$ busca pela compreensão dos dados encontrados nas publicações mapeadas, houve necessidade de se considerar que estes dados foram extraídos a partir de categorias prévias, identificando suas relações com o objeto de estudo. $\mathrm{Na}$ fase de categorização na análise de conteúdo, foi utilizado o método misto, indutivo e dedutivo, permitindo-se a escolha de categorias prévias e a abertura para a possibilidade de novas categorias nas informações emergidas no corpus do material analisado. Com base em Moraes, ao assegurar que "[...] partindo de categorias definidas 'a priori' com 
base em teorias escolhidas previamente, o pesquisador encaminha transformações gradativas no conjunto inicial de categorias." (2003 - grifo do autor).

Para a extração dos dados, foi utilizada a tabela do Excel com os seguintes parâmetros a serem analisados nos trabalhos resultantes da busca: título do artigo, ano, perspectiva teórica encontrada, objetivo, características e foco da formação, metodologia e instrumentos, procedimentos de coleta de dados e resultados.

Para tanto, foram realizadas as seguintes etapas: pré-análise, leitura flutuante, constituição do corpus, exploração do material, bem como tratamento dos resultados e interpretações baseadas na perspectiva da análise de conteúdo (BARDIN, 2011).

Diante do exposto, foram realizadas buscas com as palavras-chave já apresentadas e os seguintes refinamentos de filtragem dos trabalhos: tipo (artigo), idioma (português), data de publicação (2010 a 2018). Para a escolha deste lapso temporal, foi considerado o período posterior ao ano de criação dos institutos federais de educação através da lei 11.982/08 e as pesquisas mais recentes. Então, foram retornados 192 artigos, sendo 181 removidos, por não atenderam aos critérios de inclusão/exclusão, e selecionados 10 para leitura na íntegra. As duas buscas foram realizadas em agosto de 2018. No Quadro 1, demonstra-se bem os resultados.

Quadro 1: Resultado da busca: portal de periódico da Capes

\begin{tabular}{|l|c|c|c|}
\hline \multicolumn{1}{|c|}{ Palavras-chave } & $\begin{array}{c}\text { No de } \\
\text { achados }\end{array}$ & $\begin{array}{c}\text { Removidos devido } \\
\text { aos critérios de } \\
\text { inclusão/exclusão }\end{array}$ & $\begin{array}{c}\text { Seleção } \\
\text { para a } \\
\text { leitura na } \\
\text { integra }\end{array}$ \\
\hline $\begin{array}{l}\text { formação docente } \\
\text { continuada; } \\
\text { instituto federal }\end{array}$ & 192 & 182 & 10 \\
\hline
\end{tabular}

Fonte: Arquivo da autora, 2018.

$\mathrm{Na}$ organização dos dados para a triagem dos trabalhos encontrados, foram utilizados critérios de inclusão e exclusão na leitura dos títulos e resumos, a fim de que os vieses da pesquisa fossem minimizados. Isso com base em Koller (2014), ao defender a relevância da classificação dos trabalhos a partir de critérios pré-estabelecidos. Sendo assim, foram adotados como critérios para a inclusão dos artigos nos estudos: i) referência aos institutos federais; e ii) foco na formação docente continuada. Os critérios para se excluir os artigos nos estudos foram: i) formação docente inicial; ii) artigos que não estavam disponíveis para leitura on line; e iii) estudos com conteúdo ou resultados incompletos. O Quadro 2 apresenta os artigos selecionados após a filtragem. 
Quadro 2 - Descrição dos artigos entre 2010 e 2018 selecionados no portal de periódico da Capes

\begin{tabular}{|c|c|c|c|c|c|}
\hline N. & TÍTULO & $\begin{array}{l}\text { PALAVRAS- } \\
\text { CHAVE }\end{array}$ & AUTORES & REVISTA & ANO \\
\hline 1 & $\begin{array}{l}\text { Formação de professores da } \\
\text { educação profissional: análise de } \\
\text { produções acadêmicas. }\end{array}$ & $\begin{array}{l}\text { formação de } \\
\text { professores, } \\
\text { educação } \\
\text { profissional, } \\
\text { políticas } \\
\text { educacionais }\end{array}$ & VIEIRA & HOLOS & 2018 \\
\hline 2 & $\begin{array}{l}\text { Por que ensino como ensino? - } \\
\text { contextos e narrativas da } \\
\text { trajetória de um professor } \\
\text { formador de professores }\end{array}$ & $\begin{array}{l}\text { aprendizagem da } \\
\text { docência, } \\
\text { docência, } \\
\text { professor- } \\
\text { formador, } \\
\text { ensino }\end{array}$ & LIMA & HOLOS & 2018 \\
\hline 3 & $\begin{array}{l}\text { A formação docente para a } \\
\text { educação profissional técnica e } \\
\text { sua influência na atuação dos } \\
\text { professores do Instituto Federal } \\
\text { do Amapá - campus Macapá: um } \\
\text { estudo de caso }\end{array}$ & $\begin{array}{l}\text { educação } \\
\text { profissional, } \\
\text { formação de } \\
\text { professores, } \\
\text { prática docente }\end{array}$ & $\begin{array}{l}\text { GUEDES \& } \\
\text { SANCHEZ }\end{array}$ & HOLOS & 2017 \\
\hline 4 & $\begin{array}{l}\text { Bacharéis que se tornam } \\
\text { professores: inserção e prática } \\
\text { profissionais de engenheiros no } \\
\text { ensino superior }\end{array}$ & $\begin{array}{l}\text { engenheiros } \\
\text { professores, } \\
\text { formação } \\
\text { docente, } \\
\text { histórias de vida }\end{array}$ & $\begin{array}{l}\text { SILVA \& } \\
\text { SOUZA }\end{array}$ & HOLOS & 2017 \\
\hline 5 & $\begin{array}{l}\text { Formação de professores da EaD } \\
\text { para o uso das TIC's na Região } \\
\text { Amazônica: tutor presencial }\end{array}$ & $\begin{array}{l}\text { formação de } \\
\text { professores, } \\
\text { educação a } \\
\text { distância, } \\
\text { região } \\
\text { amazônica, } \\
\text { tutor presencial }\end{array}$ & $\begin{array}{l}\text { SILVA, } \\
\text { ZIVIERI } \\
\text { NETO; } \\
\text { SILVA } \\
\text { JÚNIOR \& } \\
\text { NASCIMEN } \\
\text { TO }\end{array}$ & HOLOS & 2017 \\
\hline 6 & $\begin{array}{l}\text { Plano Nacional de Educação e } \\
\text { seus desdobramentos sobre as } \\
\text { novas diretrizes para a formação } \\
\text { de professores da educação } \\
\text { profissional: identidades } \\
\text { profissionais em construção. }\end{array}$ & $\begin{array}{l}\text { plano nacional de } \\
\text { educação (2014- } \\
\text { 2024), } \\
\text { formação de } \\
\text { professores, } \\
\text { educação } \\
\text { profissional }\end{array}$ & SILVA & HOLOS & 2016 \\
\hline 7 & $\begin{array}{l}\text { A concepção de formação de } \\
\text { professores nos institutos } \\
\text { federais: um estudo dos discursos } \\
\text { políticos }\end{array}$ & $\begin{array}{l}\text { institutos federais, } \\
\text { formação de } \\
\text { professores, } \\
\text { concepção } \\
\text { política }\end{array}$ & $\begin{array}{l}\text { LIMA \& } \\
\text { SILVA }\end{array}$ & HOLOS & 2014 \\
\hline
\end{tabular}




\begin{tabular}{|c|c|c|c|c|c|}
\hline 8 & $\begin{array}{l}\text { A construção da profissionalidade } \\
\text { docente para a educação } \\
\text { profissional: análise de concursos } \\
\text { públicos para docente. }\end{array}$ & $\begin{array}{l}\text { profissionalidade } \\
\text { docente, } \\
\text { concurso público, } \\
\text { educação } \\
\text { profissional }\end{array}$ & $\begin{array}{l}\text { CRUZ \& } \\
\text { VITAL }\end{array}$ & HOLOS & 2014 \\
\hline 09 & $\begin{array}{l}\text { Entre o bem e o mal-estar: a } \\
\text { intensificação do trabalho docente } \\
\text { no âmbito dos institutos federais } \\
\text { de educação, ciência e } \\
\text { tecnologia. }\end{array}$ & $\begin{array}{l}\text { mal-estar } \\
\text { docente, } \\
\text { formação } \\
\text { continuada de } \\
\text { professores, } \\
\text { formação no } \\
\text { espaço de } \\
\text { trabalho, } \\
\text { pós-graduação. }\end{array}$ & $\begin{array}{l}\text { PINTO; } \\
\text { GOES; } \\
\text { KATREIN; } \\
\text { BARREIRO }\end{array}$ & $\begin{array}{l}\text { Rev. Educ. } \\
\text { por Escrito }\end{array}$ & 2013 \\
\hline 10 & $\begin{array}{l}\text { As percepções dos professores } \\
\text { da educação profissional que } \\
\text { atuam no Proeja: uma abordagem } \\
\text { reflexiva para além da formação } \\
\text { técnica }\end{array}$ & $\begin{array}{l}\text { proeja, } \\
\text { formação } \\
\text { docente, } \\
\text { formação } \\
\text { continuada, } \\
\text { educação } \\
\text { profissional }\end{array}$ & $\begin{array}{l}\text { RAGGI; } \\
\text { AZEVEDO; } \\
\text { CARDOSO; } \\
\text { VASCONCE } \\
\text { LOS. }\end{array}$ & $\begin{array}{l}\text { Rev. Expr. } \\
\text { Católica }\end{array}$ & 2013. \\
\hline
\end{tabular}

Fonte: Arquivo da autora, 2018.

Com os dados organizados, seguimos para análise e interpretação estruturadas por meio de cada uma das categorias abordadas:

- Perspectivas teóricas de formação docente na educação profissional;

- Características da formação continuada na educação profissional;

- Formação continuada e focos específicos.

\section{RESULTADOS E DISCUSSÃO}

Os trabalhos (artigos científicos) foram construídos entre 2013 e 2018. A maioria publicada na Revista HOLOS, do Rio Grande do Norte, salientando ser este um estado da federação que tem avançado nas pesquisas em torno da educação profissional das instituições federais de ensino. Inferimos que os resultados se mostram a partir das publicações encontradas diante dos filtros.

As metodologias das pesquisas foram variadas. Observa-se no quadro acima que para o artigo 1 realizou-se uma pesquisa a respeito do estado do conhecimento; os artigos 2 e 4 pautaram-se em narrativas; o de n. 3 corresponde a um estudo de caso; os de n. 5 e 9 tiveram como metodologia a pesquisa-ação; por sua vez, os artigos 6,7 e 8 são resultado de pesquisa bibliográfica; o de n.10 deixa fortes indícios de ter se tratado de uma pesquisa de campo. Diga-se de passagem que todos possuem cunho qualitativo nas suas abordagens. 
Os procedimentos para a coleta de dados e instrumentos utilizados foram os questionários (artigos 3 e 5); entrevistas (artigos 4 e 10); análise documental (artigos 8, 7 e 6); e os que explicitaram sua forma de análise de dados (artigos 1, 4 e 9) utilizaram análise de conteúdo.

Na primeira categoria, "Perspectivas teóricas de formação docente na educação profissional", cinco trabalhos citaram a perspectiva de formação docente baseada em Saberes docentes, de Tardif (2007). Dois artigos discutiram a profissionalização docente, de acordo com os autores Ambrosetti e Almeida (2008), alem de mencionaram a "teoria dos saberes docentes", baseada em Tardif $(2000,2002,2011,2012)$ e em Pimenta (2005).

No artigo 1, Formação de professores da educação profissional: análise de produções acadêmicas, Vieira (2018), as perspectivas teóricas nele empregadas, na maioria, exploraram os "saberes docentes", havendo também enfoques relativos à constituição da identidade docente. Utiliza-se como perspectiva teórica, de forma geral, os autores Gatti e Barreto (2009) e André (2011). Verificou-se também no seu desenvolvimento que a formação docente sobre a educação profissional tem sido restrita em número de pesquisas, conforme aponta Pimenta (2005), ao lançar luz sobre a necessidade de ampliação dos estudos sobre formação docente.

No artigo 2, Por que ensino como ensino? contextos e narrativas da trajetória de um professor formador de professores. Lima (2018) apresenta como bases teóricas Tardif (2002), Gòmez (1992), Zeichner (1993), Schnetzler (2000), Contreras (2002). É interessante destacar que o pressuposto teórico apresentado no resumo do trabalho não faz referência à epistemologia da prática docente da "reflexão-na-ação" de Donald Schon (2000), mas, evidencia essa abordagem, como potencialidade para melhoria das perspectivas de formação docente, a partir de Zeichner (1993), Contreras (2002), Schnetzler (2000), os quais discutem a possibilidader de um professor-pesquisador reflexivo.

O trabalho ora em discusão concebe o professor como agente de transmissão e construção de saberes. Indivíduo este que ao longo da experiência docente e diante da reflexão percebe a necessidade de efetivar formação continuada na perspectiva da análise da sua prática. Isso no intuito de entender melhor os mecanismos e dispositivos impulsionados durante a sua ação profissional, examinando os motivos do seu fazer e como ele pode transformar o que faz (re)construindo-se progressivamente.

Nesse sentido, apesar de Lima (2018) apresentar como pressuposto teórico as ideias de Tardif (2002) e reconhecer os saberes profissionais além de outros autores já elencados, os resultados do seu ensaio dialogam com a perspectiva da reflexão na ação de Schon (2000), a respeito da possibilidade de o docente refletir sua prática, pois, Lima (2018), autor do trabalho que ora é enfatizado, evidencia a formação continuada como um campo de análise de práticas, destacando esta análise realizada pelo próprio professor durante a ação profissional, examinando o que faz, ou seja, refletindo na ação. O que não foi destacado diante da ótica de Schon (2000) foi a necessidade de um profissional mais experiente. Os resultados do trabalho também corroboram 
com a afirmação de Pimenta (2005) no sentido da urgente necessidade de "repensar a formação docente".

No artigo 03, A formação docente para a educação profissional técnica e sua influência na atuação dos professores do Instituto Federal do Amapácampus Macapá: um estudo de caso, Guedes e Sanchez (2017) não explicitam sua abordagem teórica da formação de professores, mas é possível identificar Tardif (2012) e autores da educação profissional como Machado (2008), Moraes e Pedrosa (2009) no delinear do seu texto. Explorando os sentidos da educação para o trabalho, foco da educação profissional e o professor como mediador e formador de profissionais cidadãos.

Nessa perspectiva, Silva e Souza (2017), no artigo 4, também não explicitam o enfoque discursivo, mas abordam teóricos da educação a distância (EaD); identificam, sobretudo, os "saberes docentes" baseados em Tardif (2011).

No artigo 8, A construção da profissionalidade docente para a educação profissional: análise de concursos públicos para docente, identificase a "profissionalização docente", baseada em Ambrosetti e Almeida (2008), e uma formação docente de forma contextualizada. Aponta-se também para um conceito em construção, além de autores da educação profissional e saberes docentes (GUATHIER, 2006; PIMENTA, 2005; TARDIF, 2000).

O artigo 10, baseado em Kuenzer (1998), expõe a necessidade de a formação continuada não reproduzir a formação inicial, indicando-a como descontextualizada e fragmentada em bases de uma pedagogia tecnicista. Demonstra-se no referido trabalho a fragilidade dos estágios curriculares em nossa base de formação inicial e colabora-se com o pensamento de Schon (2000), quando esclarece a reflexão na ação como um arcabouço de experiências práticas, baseadas no cotidiano do professor para 0 aprimoramento da sua formação profissional.

Dessa forma, a perspectiva teórica sobre formação docente que teve maior expressividade nos artigos pesquisados foi a fundamentação em "saberes docentes" baseada em Tardif (2007) com cinco artigos, a saber: os de $\mathrm{n}^{\text {os. }} 1,2,3,4$ e 8 . Nesta abordagem, juntamente com a perspectiva de "saberes docentes", os artigos 1 a 4 relacionaram os autores com foco na formação docente para a educação profissional. O aetigo 9 , especificamente, utilizou como abordagem teórica vários autores entre formação profissional e formação continuada em âmbito geral, sendo eles Amiguinho e Canário (1994), Barroso (2003), Cunha e Fernandes (1994), Cunha (1998), Demailly (1992), Forster (2006), Marcelo Garcia (1999), Nóvoa (1992, 1995) e Pinto (2008, 2009). Por sua vez, o artigo 8, abordou o conceito de "profissionalidade docente", bem como "saberes docentes" e "formação docente para educação profissional".

Esta categoria (Perspectivas teóricas de formação docente na educação profissional) apresentou as perspectivas apontadas nos artigos, as quais, em sua maioria, basearam-se nos "saberes docentes", conforme defende Tardif (2014). Mesmo se em alguns pontos os autores não específicaram a educação profissional, os saberes docentes se fizeram 
presentes. Isso pode estar associado à importância dessa teoria, baseada na construção de saberes para a atuação enquanto docente.

$\mathrm{Na}$ segunda categoria, "Características da formação continuada na educação profissional", buscou-se agrupar os tipos, formas, modalidades e características da formação continuada evidenciada nos trabalhos analisados. Assim, oito artigos ( $\mathrm{n}^{\text {os. }} 1,2,3,4,5,6,9$ e 10) abordaram os termos: "formação docente para a educação profissional", "formação em serviço", "curso baseado na realidade", "formação reflexiva" (realidade e pensar sobre a mesma) e "programa especial para formação pedagógica". Todos com características de cursos e momentos de reflexão sobre a prática, alicerçados em momentos específicos para formação continuada, através de um curso, um programa para formação pedagógica e os já citados.

Verificou-se nos outros dois artigos, $n^{\text {os. }} 7$ e 8 , que enquanto aquele aborda a característica de uma formação crítica, emancipadora, com foco nos discursos políticos, este evidencia a profissionalidade docente. Assim, diferentemente dos demais trabalhos que se basearam em cursos para formação continuada, o de n. 8 apresnetou como característica mais evidente a permanência contínua dessa formação.

Destes trabalhos, os de $\mathrm{n}^{\text {os. }}$ 2, 3, 4, 5, 9 e 10 registram experiências práticas, vivenciadas, enquanto os de $\mathrm{n}^{\text {os. }} 1,6,7$ e 8 realizam análises de cunho teórico que podem direcionar possíveis ações para a formação docente.

Portanto, todos os trabalhos abordam a formação continuada como um momento de reflexão sobre sua prática para atualização de conhecimentos, diante de algumas modalidades de formação continuada elencadas por Romanowski (2007). As categorias encontradas nos trabalhos, de acordo com o que aponta a autora, foram: "cursos e programas sistematizados"; as formas foram as universitárias, tendo-se como finalidade essencial a transmissão da teoria escolar (que parte de problemáticas da prática docente) e da teoria interativo-reflexiva (análise da prática com pesquisa-ação). Nenhum trabalho demonstrou relato de experiências baseadas na epistemologia da prática, conforme propõe Schon (2000), por mais que na perspectiva teórica se apontasse como pressuposto.

$\mathrm{Na}$ terceira categoria "Formação continuada e focos específicos", oito trabalhos, os de $n^{\text {os. }} 1,2,3,4,6,7,8$ e 9, laçaram luz sobre a formação docente, considerando suas práticas, complementação pedagógica ou as especificidades no âmbito da educação profissional; destes apenas um tratou da capacitação pedagógica. Os de $n^{\text {os }} 5$ e 10 focaram as formações específicas para professores na modalidade da educação profissional, a exemplo do Programa Nacional de Integração da Educação Profissional com a Educação Básica na Modalidade de Educação de Jovens e Adultos Proeja e Tutoria EaD. Percebe-se a diversificação dos focos sobre a formação continuada e ausência de pesquisas sobre as abordagens mais práticas de ações já realizadas sobre programas de formação continuada desenvolvidos pelas instituições, conforme preconiza a legislação. Talvez tenha sido pela dificuldade de implementação dos direcionamentos apontados na própria legislação ou que estas ações não tenham ganhado 
respaldo científico para publicações. Nesse sentido, apenas um dos trabalhos, o artigo de n. 3, apresentou pesquisa sobre o resultado da capacitação realizada como complementação pedagógica.

O resultado da análise aponta para um crescimento nas pesquisas sobre formação docente na educação profissional, sobretudo a partir da criação dos institutos federais. Mesmo o cenário ainda apontando para uma ausência nos estudos sobre a docência por bacharéis e políticas de cursos de formação continuada no âmbito dos institutos federais.

A docência exercida nos institutos, de acordo com os resultados, demonstra que muitas vezes não há planejamento de carreira. Estes profissionais, ao ingressarem no exercício profissional, reconhecem a carência de formação pedagógica, mas não a efetuam nem cobram a realização da mesma em suas instituições.

As perspectivas teóricas apontadas nos trabalhos, em sua maioria, utilizam os saberes docentes: saber da experiência, o saber profissional e o saber pedagógico. Os poucos artigos que citam a perspectiva teórica da profissionalidade docente não demonstram desenvolvimento nem resultados que efetivem práticas baseadas nesse tipo de perspectiva. $O$ resultado encontrado sobre a necessidade de repensar a formação de professores para uma "reflexão-na-ação", não aborda o pressuposto baseado em Schon (2000), da epistemologia da prática.

Foi possível perceber algumas dificuldades apontadas para a efetivação da formação continuada na educação profissional dos institutos, como um tipo de formação baseada na análise das necessidades específicas dessa modalidade de educação. Um exemplo patente desse quadro é a atuação em modalidades e níveis de educação que se fundamenta no sentido de trabalho o qual a educação profissional dos institutos pressupõe.

Os trabalhos evidenciaram poucos relatos práticos de ações de formação continuada efetivadas. Isso pode estar demonstrando dificuldades em se efetivar ou mostrando desarticulação com as políticas nacionais de formação docente. Foram percebidas algumas sugestões de como se promover e efetivar políticas de formação aos professores da educação profissional dos institutos federais, em que se considere os critérios de seleção desses profissionais, perpassando pelo desenvolvimento de sua formação contínua e acompanhamento. Isso auxiliará a construção de uma identidade docente para a educação profissional.

\section{CONSIDERAÇÕES FINAIS}

Esta investigação teve como finalidade identificar as perspectivas teóricas e características especificas da formação dos docentes atuantes na educação profissional desenvolvida nos institutos federais de educação, uma vez que a maioria dos professores, ao ingressarem neste espaço educativo não possuem formação didático-pedagógica para a docência. Nessa perspectiva, realizou-se uma revisão sistemática em que se utilizou como procedimento a análise de conteúdo para análise dos dados.

Os resultados sinalizaram a necessidade de aprofundamento da teoria sobre formação docente. As características desta formação nos trabalhos demonstraram poucos relatos de práticas formativas e complementação pedagógica. Isso pode ser evidenciado diante das lacunas 
deixadas pela própria política voltada à formação docente, revelando dificuldades de implementação destas políticas públicas e do acompanhamento de ações para formação docente no âmbito dos institutos federais. A ausência destes suportes pode desestimular os professores a enfrentarem os dilemas da sala de aula e a investirem em sua formação continuada.

Sempre haverá dificuldades na prática pedagógica. Porém, investir numa formação continuada para que o docente renove continuamente seus conhecimentos é a ferramenta de fortalecimento do seu exercício docente. $O$ reconhecimento da sua prática pedagógica, reuniões para solucionar os principais problemas da aprendizagem e o auxílio de educadores experientes são proposições que auxiliariam seu desenvolvimento profissional.

Esta investigação teve o propósito de fomentar a aproximação do público envolvido com a temática da formação docente continuada nos institutos federais. A mesma pretendeu também finalizar as discussões e teve a intenção de ampliar o debate demonstrando a importância em se priorizar estudos e ações voltadas para aprimoramento de uma formação de professores baseada nas necessidades formativas específicas de cada modalidade escolar.

Por fim, é um campo de pesquisa que necessita de atenção maior e de mais investigações, campo este em que se priorize a análise da prática profissional do docente, baseada em sua atuação na educação profissional.

\section{REFERÊNCIAS}

BARDIN, L. Análise de conteúdo. São Paulo: Edições 70. 2011.

BRASIL. Lei 11.892/2008. Institui a Rede Federal de Educação Profissional, Científica e Tecnológica, cria os Institutos Federais de Educação, Ciência e Tecnologia, e dá outras providências. Brasília, DF: Casa Civil, 2008. Disponível em: https://www.planalto.gov.br/ccivil03/ato2015-018/2016/decre to/d8752.htm. Acesso em: dez. 2019.

BRASIL. Decreto n. 8.752, de 9 de maio de 2016. Dispõe sobre a política nacional de formação dos profissionais da educação básica. Brasília, DF: Casa Civil, 2016. Disponível em: https://www.planalto.gov.br/ccivil03/ato20 15-018/2016/decreto/d8752.htm. Acesso em: dez. 2019.

BRASIL. Lei n. 12.772/2012. Dispõe sobre a estruturação do Plano de carreiras e cargos de magistério federal e dá outras providências. Brasília, DF: Casa Civil, 2012a. Disponível em www.planalto.gov.br/ccivil_03/_ato 2011-2014/2012/lei/l12772.htm. Acesso em: 12 jun. 2018.

BRASIL. Lei n. 9.394/1996. Estabelece as diretrizes e bases da educação nacional. Brasília, DF: Casa Civil, 1996. Disponível em: http://www.planalto. gov.br/ccivil03/leis/L9394.htm. Acesso em: jan. 2020. 
BRASIL. Ministério da Educação. Resolução n. 6, de 20 de setembro de 2012. Define Diretrizes Curriculares Nacionais para a Educação Profissional Técnica de Nível Médio. Brasília, DF: CNE, 2012b. Disponível em: http://portal.mec.gov.br/index.php?option=com_docman\&view=download\&alia $\mathrm{s}=11663$-rceb006-12-pdf\&category _ slug=setembro-2012-pdf\&ltemid=30192. Acesso em: jan. 2020.

CALDAS, L. A formação de professores e a capacitação de trabalhadores da EPT. In: . (org.). Os institutos federais: uma revolução na educação profissional e tecnológica. Brasília; São Paulo: Santilhana; Moderna, 2011. p. 33-45.

CHARLIER, E.; PAQUAY, L.; PERRENOUD, $\mathrm{P}$ (org.). Formando professores profissionais: quais estratégias. quais competências? 2. ed. Porto Alegre: Artmed, 2008.

CRUZ, S. P. S.; VITAL, T. R. S. A construção da profissionalidade docente para a educação profissional: análise de concursos públicos para docente. HOLOS, [Natal], v. 2, p. 37-46, 2014.

FRANCO, M. L. P. B. Análise de Conteúdo. Brasília: Editora Plano, 2003. (Série Pesquisa em Educação, 6).

GATTI, B.; BARRETTO, E. S. Professores do Brasil: impasses e desafios. [S.I.]: Unesco Representação no Brasil, 2009.

GUATHIER, C. et al. Por uma teoria da pedagogia. Injuí: Ed.Unijuí, 2006.

GUEDES, I. A. C; SANCHEZ, L. B. A formação docente para a educação profissional técnica e sua influência na atuação dos professores do Instituto Federal do Amapá-campus Macapá: um estudo de caso. HOLOS, [Natal], v. 7, p. 238-252, 2017.

KOLLER, S. H.; COUTO, P. M. C. P.; HOHENDORFF, J. V. (org.). Manual de produção científica. Porto Alegre: Penso Editora, 2014.

KUENZER, A. Z. Formação de professores para a educação profissional e tecnológica. In: DALBEN, A. I. L. F. et al. Convergências e tensões no campo de formação e do trabalho docente. Belo Horizonte: Autêntica, 2010, p. 497-518.

LIMA, F. B. G.; SILVA, K. A. A concepção de formação de professores nos institutos federais: um estudo dos discursos políticos. HOLOS, [Natal], v. 2, p. 3-12, 2014.

LIMA, F. J. Por que ensino como ensino? Contextos e narrativas da trajetória de um professor formador de professores. HOLOS, [Natal], v. 2, p. 259-275, 2018.

MENESES FILHO, A; COSTA, M. A. Formação de professores para a educação profissional e tecnológica: o olhar da legislação (1917-2017). In: 
COLÓQUIO NACIONAL, 4., 2008; COLÓQUIO INTERNACIONAL, 1., 2008, Natal. Anais ... Natal: IFRN, 2017. p. 1-12.

MORAES, L. C. S.; PEDROSA, E. M. P. A formação de professores para a educação profissional: um debate necessário. In: CHAVES, V. J.; CABRAL NETO, A. C.; NASCIMENTO, I. V. (org.). Políticas para a educação superior no Brasil: velhos temas e novos desafios. São Paulo: Xamã, 2009.

MORAES, R. Uma tempestade de luz: a compreensão possibilitada pela análise textual discursiva. Ciência \& Educação (Bauru), v. 9, n. 2, p. 191-211, 2003. Disponível em: http://www.scielo.br/scielo.php?pid=S151673132003000 200004\&script=sci_arttext. Acesso em: dez. 2019.

MORAES, R. GALIAZZI, M. C. Análise textual discursiva. Injuí: Editora Unijuí, 2007.

MOROSINI, M. C. Estado de conhecimento e questões do campo científico. Educação, Santa Maria. v. 40. n. 1. p. 101-116. jan./abr. 2015.

MOURA, D. H. A formação de docentes para a educação profissional e tecnológica. Rev. Bras. Educ. Profiss. e Tecnol., v. 1, n. 1, p. 23-38, 2008.

PACHECO, E. M. Os institutos federais: uma revolução na educação profissional e tecnológica. São Paulo: Moderna, 2011.

PERRENOUD, P. et al. Formando professores profissionais: três conjuntos de questões. In: Formando professores profissionais: quais estratégias? quais competências? 2. ed., rev. Porto Alegre: Artmed, 2001. p. 11-12.

PIMENTA, S. G. (org.). Saberes pedagógicos e atividade docente. São Paulo: Cortez, 2005.

PIMENTA, S. Formação de professores: identidade e saberes da docência. In: PIMENTA, S. G. (org.). Saberes pedagógicos e atividade docente. São Paulo: Cortez Editora, 1999. p. 15-34.

PINTO, C. L. L. et al. Entre o bem e o mal-estar: a intensificação do trabalho docente no âmbito dos institutos federais de educação, ciência e tecnologia. Educação Por Escrito, [S.I.], v. 4, n. 1, p. 44-58, 2013.

RAGGI, D. G. et al. As percepções dos professores da educação profissional que atuam no Proeja: uma abordagem reflexiva para além da formação técnica. Rev. Expressão Católica, [S.I.], v. 2, n. 1, p. 89-108, 2013.

ROMANOWSKI, J. Formação e profissionalização docente. 3. ed. Curitiba: Ibpex, 2007.

SALLES, N.; COSTA, R.; SALLES, F. Docência na educação profissional e tecnológica: uma proposta de formação continuada no âmbito do espaço escolar. Rev. Triângulo, [S.I.], v. 9, n. 2, p. 86-97, 2016.

SCHÖN, D. A. Educando o profissional reflexivo: um novo design para o ensino e a aprendizagem. Tradução: Roberto Cataldo Costa. Porto Alegre: Artes Médicas Sul, 2000. 
SILVA, F. L. G. R. Plano Nacional de Educação e seus desdobramentos sobre as novas diretrizes para a formação de professores da educação profissional: identidades profissionais em construção. HOLOS, [Natal], v. 6, p. 156-177, 2016.

SILVA, J. C. et al. Formação de professores da EaD para uso das TIC's na Região Amazônica: tutor presencial. HOLOS, [Natal], v. 2, p. 214-228, 2017.

SILVA, S. H. S. C.; SOUZA, F. C. S. Bacharéis que se tornam professores: inserção e prática profissionais de engenheiros no ensino superior. HOLOS, [Natal], v. 5, p. 197-213, 2017.

TARDIF, M. Saberes docentes e formação profissional. 8. ed. Petrópolis: Vozes, 2014.

VIEIRA, M. M. M. Formação de professores da educação profissional: análise de produções acadêmicas. HOLOS, [Natal], v. 2, p. 243-258, 2018. 